\title{
Internal controls and human capital reengineering to improve financial performance in firm Professor Philip Law
}

Associate Head of the Department of Accounting and Information Management

Faculty of Business Administration

University of Macau, Macau, China

Email: PLaw@um.edu.mo

China

\section{ABSTRACT}

Financial and internal controls are important to the success of firms. $A B C$ group is undergoing internal controls and knowledge reengineering in the company to improve the group's operations and financial performance. Various measures are implemented and the results provide insights for firms to succeed in today's competitive financial markets.

\section{Keywords: internal controls, financial performance, reengineering, human capital}

\section{Introduction}

\subsection{Background}

The ABC Group has been operating in Hong Kong for over 25 years. It started as a Chinese seafood restaurant that catered mainly to tourists. Its business had always been successful. The local people used to associate the restaurant as a tourist spot meaning the food tended to be expensive and the taste was catered to foreigners. In recent years, the owners had capitalized on the success story of the restaurant to further develop it into a catering group that now consists of the original Chinese seafood restaurant which remains the mainstay of the group, an upmarket fine dining restaurant that caters to businessmen, a western café that specializes in fusion food, a BBQ type casual open restaurant, and cake shops. Most of the employees had been with the seafood restaurant for a long time. Through years of service in good times, the average wages of the employees were above the market average. In return for a good income, the employees had a deep attachment to the group. This had created a very close relationship with the customers a lot of them had been repeated customers for many years. Since the Asian Financial Crisis in 1997, the business had gradually come down. Overseas tourists dropped and the price had to be reduced as well. As a result, the Group incurred losses for the first time in many years. Instead of a one-sided view of drastically cutting costs, the owners took the bold decision amidst a gloomy economy to expand the restaurant into a culinary kingdom as it is today. It would cost much less to expand under gloomy economic conditions.

\subsection{Organization Structure}

A new general manager was appointed for the new kingdom. He established four business units, namely, the seafood restaurant, the fine dining restaurant, the fusion café, and the open restaurant, and cake and candies retailing. Each of these units had a manager who would be responsible for the overall operations of the unit under him. Traditionally the general personnel functions were limited to hiring and firing of and compiling a roster for staff. No formal training was given to recruits. A new human resources manager was hired to run the new human resources department. The general manager gave a clear mandate to the HR manager that he wanted formal training to be given to all new staff, as well as on-going development programs for existing staff.

\subsection{Performance Management}

Previously there was no stated policy on performance appraisal and reward system. Most of the staff was considered as similar to laborers. They were paid a fixed salary with a uniform annual adjustment. There were virtually very few salary disparities. The general manager completely revamped the system. A performance appraisal system has been established to peg salary adjustment with performance.

\subsection{IT Usage}

A new website was designed for the group by professional web designers to enhance the group's image and facilitate the introduction of the group's services to potential customers from afar. An in-house designer was recruited to look after and update the website from time to time. A new point-of-sale system was also installed to enable swift ordering and an efficient workflow and coordination between the service attendants and the kitchen. All the function rooms are equipped with audiovisual and Internet facilities to enable customers to hold business conferences.

\subsection{Corporate Culture}

The new management intends to create a coherent relationship among the staff. On the other hand, a casual atmosphere is intentionally instituted to promote goodwill trust among staff as well as encourage them to propose innovative ideas to management. While a proper organizational structure is devised, management intends to give the staff enough room to be creative in the culinary art that can be easily stifled by too rigid rules. 


\section{CCenter for Promoting Education and Research (CPER) USA}

WWW.cpernet.org

\section{Identification of Knowledge Assets}

Although the group has been through different times of ups and downs, the valuable intangible assets only grow with time. The people and the records are the most important knowledge assets that the group can tap to enhance its corporate value. One of the most valuable human capitals of this organization is the experience and knowledge of the staff. As most of the staff has worked for the group for a long time, they know many repeating customers by heart. The habits and preferences of customers are important data and information. Addressing a customer by name and recalling their favorite dishes is one of the best loyalty programs that need minimal costs to maintain. Chefs are another important human capital. Through years of cooking and creating new dishes, they have developed a set of cooking skills that cater to the taste of most customers. This helps to retain customers. The menu serves as an important record. It reflects the more popular dishes that cater to the tastes of most customers. The menus indirectly record the changes in customers' tastes at different times. This is yet another important loyalty programmer as repeat customers can always find their favorite dishes on the menu. This is the structured capital of the group. The computer records of the orders and customer names offer an important source of information and data. The records show the pattern of change in customer tastes at different times. Furthermore, the accounting records provide a good indication of the high and low seasons. This enables material acquisition and staff rotations to be done more efficiently and effectively. Restaurant operations have a few important interfaces interface with customers, staff, and suppliers. Over time, the long-standing suppliers also know the pattern of acquisition well and can do better preparation work in providing the right quantity of materials to the restaurant. This enables them to schedule their orders in such a way that will reduce costs. The ABC Group does not have a coordinated and well-structured method of identifying the level of knowledge that exists in the organization. This may result in the duplication of efforts by different functional areas in search of the same knowledge. They should identify the key knowledge holders in the functional areas like purchasing, marketing, human resources management, accounting, kitchen, and others. Equally important is the identification of the secondary sources of knowledge used by staff in these functional areas. A census of the knowledge from these sources will provide a clear picture and a ready reference for the expertise that is available in the Group.

Each unit within the organization can set up a focus group made of experts, to locate the knowledge within their units. An organization-wide knowledge library can be set up by accumulating the result of the focus group studies from all units. This will evolve into a knowledge map that will guide users on where to find the specific knowledge required in carrying out specific duties. Good knowledge of how customers and suppliers see an organization is a vital tool for planning. This knowledge enables the organization to react promptly and effectively to customer's/suppliers behaviors.

\section{Reflection of Existing Knowledge}

The ABC group falls within the range of small to medium enterprises with little or no formal knowledge management structure. Apart from some explicit knowledge the organization had acquired in its dealings with customers, suppliers, and others, most of the knowledge that exists in the organization is embedded in the minds and heads of the workers (tacit knowledge) who over the years have learned a lot on the job. The organization has distinguished itself within the industry in terms of good products and excellent service delivery, relying on the tacit knowledge of its employees. A close look at the kitchen staff shows that the head chef and other kitchen employees have perfected their methods of preparing different types of dishes. A lot of knowledge used in their daily schedules is not codified. Most of the staff was employed with very little knowledge on how to prepare most exclusive menus of the restaurant, but over time, they have acquired the relevant knowledge to become experts in the preparation of different delicious dishes.

\subsection{Turning Tacit Knowledge into Explicit Knowledge}

There is a need for the restaurant to embark on the documentation of the abundant tacit knowledge within the organization, for sustainability and application in training newly employed staff. Presently new employees undergo induction courses conducted by the more experienced existing workers, who orally give them instructions on their new jobs. The induction exercises do not follow a consistent pattern of knowledge sharing but depended on who are the instructors and what they have in their heads to share with the inductees. The situation with the kitchen staff reflects an organizationwide culture. Other functional areas in the organization also depend mainly on informal knowledge sharing through communities of practice and other social networks within the system. The organization has not embraced efficient knowledge management practices involved in the process of generation, codification, transfer, and application of knowledge (Alavi \& Leidner, 2001). The organization should classify its existing knowledge into individual and organizational knowledge as a prelude to codification. Organizational knowledge comes from within groups of individuals. This leaves a gap between what the individuals know and what the organization knows (Alavi \& Leidner 2001). The Group has to capitalize on the abundant individual knowledge by turning most of it into organizational knowledge to be able to derive the advantages of strategic knowledge management (Pfeffer \& Sutton, 2000). Both the individual and organizational knowledge need to be modified to permit more meaningful knowledge sharing that will boost organizational learning and reduce any existing gap. It follows the Confucian 
wisdom that what people hear, they forget, what they see, they remember and what they do, they understand. Knowledge creation and flow in this organization should be codified to encourage easy and enduring diffusion of such knowledge in the workers. The work processes and procedures in different functional areas in the organization should be closely monitored to identify the existing tacit knowledge in the employees, to document the codifiable ones into explicit knowledge. For example, a recipe book that will put together individual knowledge on how to cook dishes can be prepared for different dishes. This process converts tacit knowledge into explicit knowledge that can be used to train and guide employees who have zero knowledge of preparing these dishes, to prepare them. This will equally reduce inherent constraints in the process of knowledge transfer to the barest minimum and enhance organizational learning and formal knowledge flow.

\subsection{Verifying the Utility of the Tacit Knowledge}

Some tacit knowledge is shrouded in uncertainty as it is based on personal experience and intuition whose accuracy may be called to question (Newell S. et al, 2002). The tendency is that most people are not willing to write it down for fear of being wrong but may be willing to share it informally. Some knowledge may be subject to frequent changes such that its relevance may have changed before the process of codification is completed and in some instances, the cost of codification may exceed what it will take to learn such knowledge by trial and error. (Newell S. et al 2002). The above shortcomings put together, inform a need, for the ABC Group to adopt the 'focus group approach' for converting tacit knowledge to explicit knowledge. Groups of employees should be created within the functional departments or by their expertise, to identify the knowledge holders in their various areas. Existing tacit knowledge so identified should be scrutinized and subjected to peer review to determine its value, usefulness, and need for codification. This will ensure that the best ways to use such knowledge are documented for organization-wide application.

\section{Recommendations for Improving Internal Controls and} Knowledge Sharing

According to the IRSA approach (Davidson and Voss, 2002), the group can adopt many sharing strategies to enhance the knowledge management ability of the group.

\subsection{Creation of a Knowledge Sharing Climate Culture}

A sharing climate culture should be created and cultivated in the group. A sharing climate can help the employees acquire knowledge and replenish their creativity and innovation in the work. (Seviby and Simons, 2002) suggest a collaborative climate may influence the effectiveness of knowledge work in the organization. The collaborative climate may include every "ba" (Nonaka and Konno, 1998) within the group. Thus the tacit and explicit knowledge can be more effectively conveyed and shared with all the knowledge workers within the group.

\subsection{Knowledge Available Everywhere in the Group}

There are two ways to make knowledge available (Yang, 2004) throughout the group, according to the IRSA approach (Davidson and Voss, 2002). These are internal knowledge learning and external knowledge learning. The former can be approached by the encouragement of the employees to learn from other knowledge workers. This can be achieved by hosting weekly group workshops and focus groups (Davidson and Voss, 2002) for all levels of employees. For example, waiters can gather in a group workshop to share their working knowledge through a storytelling approach. More external functions such as social gathering can enhance the communities of practice (COP) effectiveness. External knowledge learning can be achieved by the means of obtaining and sharing knowledge with the alliance partners, suppliers, customers, and government bodies. These can enhance collaboration and trust in the workplace and improve knowledge-sharing effectiveness. The companion trust and competence trust (Newell, 2002) will inevitably be increased between the knowledge workers in the restaurant group.

\subsection{Create the Knowledge Map}

Davidson and Voss (2002) suggest creating a knowledge map in the organization where employees can access the knowledge they needed conveniently. The group can create "Yellow Pages" where it will list the essential key contact knowledge person of each respective department. For example, whenever the restaurant managers foresee there will be increased demand for certain festival foods by the weekend, they would access the "Yellow Pages" and contact the key purchasing knowledge supervisor to replenish the festival food for just in time purchasing. This not only helps speed up the knowledge sharing and coordination but also minimizes the storage costs for the group.

\subsection{Create the Information and Communication Technologies (ICT)}

The group can adapt the information and communication technologies (ICT) to implement a knowledge management system within the group (Newell et al, 2002). The knowledge management system comprises the intranets, emails, and databases. This ICT system can help the unit managers access and share the knowledge which is captured in the ICT system. For example, one-unit manager can access a customer complaint in another unit through the ICT system and thus will minimize repeated incidents in other branches. The knowledge managers can share the knowledge by capturing the information and storing it in the group ICT system.

\subsection{Create Less Hierarchical Structure}

The group should adopt a more flexible and less hierarchical structure (Handy, 1989). Fewer layers of middle managers should be made in the group and more power 


\section{(C) Center for Promoting Education and Research (CPER) USA}

WwW.cpernet.org

devolved down the hierarchy. As a result, the employees will have more autonomy and empowerment in their work. Teamwork is encouraged for employees and can enhance knowledge creation and speed up the knowledge-sharing process. The employees especially the frontline staff such as the waiters, should be regarded as knowledge assets rather than just mechanical workers. The group can adopt Handy's (1989) Shamrock structure for the proposed organizational structure. It consists of (1) the core knowledge workers such as key knowledge staffs in each department, (2) the contractors such as the specially invited chefs from overseas, and (3) flexible labor force such as singers and dancers to perform at weekends.

\subsection{Utilize Cross-Functional Teams and Expertise}

The group should bring expertise from different departments to discuss and share their knowledge through more informal gatherings within the group. This would inevitably create the "ba" where the employees from different units and departments will share their knowledge through storytelling or communities of practice in an informal and relaxing environment.

\subsection{Appoint the Chief Knowledge Manager}

The group could appoint a chief knowledge manager to oversee the whole content of the knowledge stocks and information flow in the information and communication technologies (ICT) system. Davidson and Voss (2002) agree that the chief knowledge manager should act as a champion and leader for the knowledge management work. Under the leadership of the chief knowledge manager, the response rate to different knowledge workers in the group will be faster. This will also effectively reduce the lead times for accessing knowledge and expertise from the knowledge workers within the group.

\subsection{Create Knowledge Sharing Award}

The group management should reward the employee for knowledge-sharing behavior monthly (Davidson and Voss, 2002). The rewards can be intrinsic and extrinsic such as praise, promotion, and monetary rewards (Yang, 2004). By creating the knowledge-sharing award, Smith (2001) suggests this could encourage employees to develop a knowledgesharing culture and motivate the knowledge workers correspondingly.

\subsection{Create the "Cyber Knowledge Café"}

Wiig (1999) suggests creating a "knowledge café" which enables the employees to meet together and share their knowledge in an informal environment. The group can create a cyber-knowledge café or tea house to enable the different levels of employees such as key knowledge workers, managers, waiters, and chefs to share their knowledge, build up social interactions and interpersonal relationships with one another. Gronau (2002) describes the knowledge café in the IT way that this is a knowledge management system maintained in the organization. The knowledge workers from different group units can access and share the knowledge available within the group. This will again inevitably speed up the knowledge-sharing process.

\section{Conclusion}

In general, when the staff has shared and/or learned the required knowledge, they should be encouraged to further share and discuss openly with one another within and outside the concerned department. Indeed, the ability of the company to build up this culture, and to have staff talk and listen to one another, is the key to the application of knowledge management (KM) and the efficient use of human capital. The degree of cross-functional exposure is crucial to the success of the KM application. The appointment of a Knowledge Manager would be a good idea to establish and maintain the sharing culture as previously mentioned. To inject the concept of KM application within the new performance appraisal system, the current performance appraisal system should be revised to reflect the ability of individuals to apply KM apart from other performance measures. The formal appraisal should therefore be able to capture the degree of KM application over their daily routine operations, like the number of different dishes created within the performance period for a cook. By adding this desired performance/outcome as part of core competence for assessment, a direct and positive motivation for all to pursue KM application at all times can be established. Similarly, the active knowledge-sharing behaviors may also be spotted as part of the key performance indicators (KPIs) for all staff. Finally, the whole performance appraisal should be linked up with not only the regular salary adjustments but also the staff long term career development. The whole arrangement must be made known and well communicated to all concerns to reap the full advantage of this mechanism to improve financial performance. Finally, when all the knowledge is demonstrated to produce better performance, the ABC Group will require going far beyond application. It should create different systems to embed the knowledge into its normal operating procedures and change it into structural capital, to take full benefits of KM. In this regard, knowledge management and internal controls reengineering provide a solid opportunity for the $\mathrm{ABC}$ group to maintain a competitive edge and achieve better financial performance in the long run.

\section{References}

Davidson, C., \& Voss, P. (2002). Knowledge Management. Auckland: Tandem Press.

Gronau, N. (2002). The knowledge café-A knowledge management system and its application to hospitality and tourism. Journal of Quality Assurance in Hospitality and Tourism, 3(3), 75-88. http://dx.doi.org/10.1300/J162v03n03_05 
www.sciedu.ca/ijfr International Journal of Financial Research Vol. 5, No. 3; 2014 Published by Sciedu Press 115 ISSN 1923-4023 E-ISSN 1923-4031

Handy, C. (1989). The Age of Unreason. Harvard Business School Press.

Newell, S., Robertson, M., Scarbrough, H., \& Swan, J. (2002). Managing knowledge work. London: Macmillan.

Nonaka, I., \& Konno, N. (1998). The Concept of "Ba": Building a foundation for knowledge creation. California Management Review, 40(3), 40-54. http://dx.doi.org/10.2307/41165942

Smith, E. (2001). The role of tacit and explicit knowledge in the workplace. Journal of Knowledge Management, 5(4), 311-321. http://dx.doi.org/10.1108/13673270110411733

Sveiby, K.E., \& Simons, R. (2002). Collaborative climate and effectiveness of knowledge work- an empirical study. Journal of Knowledge Management, 6(5), 420-433. http://dx.doi.org/10.1108/13673270210450388

Wiig, M. (1999). Comprehensive knowledge management. Working paper, Knowledge Research Institute Inc, TX, USA.

Yang, J. (2004). Job related knowledge sharing: comparative case studies. Journal of Knowledge Management, 8(3), 118-126. http://dx.doi.org/10.1108/13673270410541088 